\title{
Representações de masculinidade na dança contemporânea
}

Giuliano Souza Andreoli*

\begin{abstract}
Resumo: Esse artigo analisa as representações culturais de gênero masculino no universo da dança contemporânea. Para sustentação da problemática da pesquisa, lança mão do referencial teórico dos Estudos Culturais e dos estudos pósestruturalistas de gênero. Utiliza-se da metodologia de pesquisa qualitativa, coletando informações através de entrevistas, para analisar narrativas de bailarinos. Discute a idéia bastante difundida da dança como algo mais associado a mulheres ou homens homossexuais, percepção que atua como uma barreira ao ingresso dos homens em quaisquer atividades rítmicas ou expressivas.

Palavras-chave: Dança. Identidade de Gênero. Corpo humano.
\end{abstract} Masculinidade.

\section{INTRODUÇÃo}

"Ninguém nasce homem, torna-se homem". Essa frase tem sido recorrente nos estudos sobre as masculinidades (BADINTER, 1993; CUNHA JUNIOR, 2000; BONOMO; BARBOSA; TRINDADE, 2008; BANDEIRA, 2009) ${ }^{1}$. Inicio esse artigo com ela, pois nos traz a ideia de que a masculinidade, assim como a feminilidade, também é construída através dos processos de socialização. É portanto uma construção histórica e cultural, que pretendi, aqui ${ }^{2}$, investigar em sua relação com a prática artística da dança.

A opção por enfocar masculinidades no contexto da dança se deve à condição singular que ocupa o homem dentro desse universo. Diversos autores (VAN DYKE, 1992; STINSON, 1995;

\footnotetext{
*Licenciado em Educação Física. Mestre em Educação. Professor de Educação Física da rede municipal de ensino de Porto Alegre. Porto Alegre, RS, Brasil.

E-mail: giulianosouzandreoli@yahoo.com.br.

${ }^{1}$ Essa frase é na verdade uma paráfrase da famosa frase de Simone de Beauvoir que havia marcado o início dos estudos de gênero - "Ninguém nasce mulher: torna-se mulher" (BEAUVOIR, 1974, p.301.)

${ }^{2}$ Nesse artigo, procuro sintetizar as discussões que fiz ao longo de minha dissertação de mestrado sobre as representações culturais de gênero na dança contemporânea (ANDREOLI, 2010a).
} 
GOELLNER, 2001; SARAIVA, 2003) observam que em nossa cultura a dança caracteriza-se, no sentido geral, como um universo predominantemente feminino. Tal problematização adentra também o terreno da sexualidade, uma vez que os homens que dançam são geralmente considerados homossexuais (Souza, 2007), sendo tal associação quase sempre feita dentro de um registro homofóbico, de desvalorização dessa orientação sexual.

Dessa forma, estudar a inserção dos homens na dança significa estudar homens que não se enquadram dentro das normas culturais hegemônicas de gênero e sexualidade. Isso é importante para compreender melhor o funcionamento dessa norma, como ela funda hierarquias e como repercute na vida dos sujeitos. Por outro lado, é uma maneira de demonstrar a não existência de um único tipo de masculinidade, enfatizando que as identidades humanas são múltiplas, plurais e não atendem a um modelo universal.

Dentro do contexto da dança, alguns estudos (SOUZA, 2007; SANTOS, E. C, 2009; SANTOS, T. M., 2009) têm observado que as representações hegemônicas de gênero e as regulações sociais que estas impõem não se manifestam de forma igual em todas as modalidades de dança. Assim, para essa pesquisa, procurei adotar como recorte um contexto cultural específico, o universo da chamada 'dança contemporânea'. A partir da problemática, procurei mapear a trajetória e os contextos sociais da construção das masculinidades de bailarinos de companhias e grupos de dança contemporânea, na cidade de Porto Alegre.

\section{REFERENCIAL TEÓRICO E REVISÃo}

Gênero, em sua definição mais básica refere-se às formas como são constituídas as noções culturais de masculino e feminino. É um sistema de significação que orienta, através da linguagem, as formas de vivermos as masculinidades e as feminilidades, organizando assim toda a vida social (MEYER, 2004). Gênero é também uma "forma primária de dar significado às relações de poder" (SCOTT, 1995, p. 86), tendo ao longo da história constituído inúmeros processos de desigualdade social.

Wovimento, Porto Alegre, v. 17, n. 01, p. 159-175, janeiro/março de 2011. 
Gênero é também a origem discursiva do sexo (BUTLER, 2003), o que significa dizer que ele constitui as representações culturais de sexualidade. Ele é um sistema simbólico que depende da regulação e da normatização das práticas sexuais para poder afirmarse. Em nossa cultura, durante muito tempo operou de maneira muito forte uma lógica heteronormativa, isto é, que apresentava a heterossexualidade como a norma de gênero. A heteronormatividade, isto é, a "obsessão com a sexualidade normalizante, através de discursos que descrevem a situação homossexual como desviante" (BRITZMAN, 1996, p.79), é o que dá origem à homofobia social.

As normas culturais de gênero sempre dependeram de mecanismos para serem continuamente reforçadas. Tais mecanismos têm sido nomeados como pedagogias do gênero e da sexualidade (LOURO, 2004). Essas incluem as diversas práticas sociais, como rituais ou rotinas, que servem para naturalizar os regimes de regulação sobre os indivíduos. Tais práticas incluem, entre outras coisas, as maneiras de gesticular e de movimentar-se consideradas mais apropriadas ao corpo masculino ou feminino. Conforme abordei em um artigo anterior (ANDREOLI, 2010b), compreendo que a dança é uma prática social particularmente bastante implicada nessas pedagogias corporais do gênero e da sexualidade.

Assim, por exemplo, é possível observar que, desde a sua "invenção", no século XV, até o século XVIII, o balé clássico operou por muito tempo uma eficiente pedagogia da masculinidade. Ao lado da esgrima e outras práticas corporais, era um meio eficaz para "formar" homens - isto é, para generificar corpos masculinos. Estava associado a um modelo de masculinidade hegemônico, denominado por Kimmel (1998) de o "patriarca gentil": o nobre europeu, aristocrático, refinado, elegante, que obtinha seu valor e "provava" sua masculinidade através da exibição de gestos corporais suaves e delicados e de uma certa sensualidade. A sociedade, nessa época, considerava a dança uma atividade masculina natural. Com observa Hanna (1999), em contrapartida, não era considerada uma prática própria para as mulheres.

Na metade do século XVIIII e início do século XIX, essa situação se inverte. Os ideais modernos de masculinidade são in-

Wovimento, Porto Alegre, v. 17, n. 01, p. 159-175, janeiro/março de 2011. 
ventados, em resposta a uma necessidade crescente de organização das relações sociais, proveniente de um novo processo civilizador. A Revolução Industrial e o surgimento das sociedades burguesas faz emergir uma nova representação de masculinidade associada com a produção, a eficiência, a racionalidade e a produtividade (HANNA, 1999). Nessa época, a distinção entre homossexualidade e heterossexualidade é criada, e novas normas são estabelecidas para o gênero e a sexualidade masculinas. A homossexualidade, tida como um desvio da natureza, passa a ser considerada uma sexualidade degradada. E, em paralelo, ela é também signo de um gênero degradado, ou falta de masculinidade.

No século XIX, emerge nos Estados Unidos e na Europa o modelo cultural do self-made-man: o empresário urbano, devotado ao trabalho, extremamente competitivo e ansioso. Um modelo de homem do qual se requer provas constantes de sua masculinidade, sendo a aquisição palpável de bens materiais uma evidência de seu sucesso (KIMMEL, 1998). Em suma, uma representação cultural hegemônica de masculinidade que dá muita importância à questão do sucesso econômico, e que adquire e demonstra o seu valor por competir com outras masculinidades no mercado.

Mas para se instaurar, essa nova representação cultural de masculinidade precisou negar os modelos de masculinidade anteriores. Como observa Kimmel (1998), "o verdadeiro homem americano [o novo modelo] era vigoroso, másculo e direto, não era afetado e corrupto como os europeus" (KIMMEL, 1998, p. 113). Já o modelo anterior foi, então, definido como "um pavão europeu afetado, uma bichinha. (ibid). Assim, a partir do século XIX, embora a heteronormatividade tenha estado presente tanto nas construções culturais hegemônicas do masculino quanto do feminino, a homofobia passou a operar como um mecanismo privilegiado dentro das estratégias de regulação da masculinidade.

O balé, com a sua estética originária de um modo de se movimentar da nobreza do século XVIII e, portanto, do modelo de masculinidade anterior, passa a ser um dos símbolos que essa nova representação procurou negar. Assim, foi no interesse em sustentar esse novo modelo hegemônico de masculinidade que surgiram

Movimento, Porto Alegre, v. 17, n. 01, p. 159-175, janeiro/março de 2011. 
representações que construíram a noção de que homens que se aproximam da dança não são totalmente homens. Tal mudança ao nível da representação cultural de gênero determinou, desde então, que se associasse o homem que dança balé à idéia de "efeminação".

Com essa desvalorização da dança como uma atividade masculina, o balé passou a ser associado ao feminino, ocorrendo assim a inversão. Surgiu o romantismo estético no balé ${ }^{3}$ que tomou a mulher como figura central do palco, e introduziu algumas mudanças, como, por exemplo, a sapatilha de pontas. Passou a haver uma conotação feminina na dança (HANNA, 1999). No entanto, como observa ainda Hanna (1999), se no palco a mulher passou a ser o centro das atenções, a profissão bailarina era socialmente desvalorizada, contando com pouca remuneração, sendo geralmente associada à vulgaridade. Além disso, as companhias eram dirigidas por homens, estando as mulheres subordinadas à autoridade masculina.

Até os dias de hoje, persiste essa forte representação cultural ocidental que associa o balé à feminilidade e à homossexualidade. Mesmo após o surgimento da vertente russa do balé, por exemplo, na qual a figura do homem em cena é revalorizada, a ideia de uma dança que evoca um ideal corporal de "não-masculinidade" permanece "colada" a essa dança. Em outras danças, ela não se revela tão forte, e os homens não aparecem em menor número, como evidenciam algumas pesquisas: nas tradicionais danças folclóricas (SOUZA, 1994), por exemplo, ou no moderno Hip Hop (SANTOS, E. C., 2009). No entanto, o balé clássico tem um estatuto como representativa de todo o universo da dança, ditando suas normas estéticas, como analisa Souza (2007). Assim, quanto mais uma prática se aproxima do balé em seus movimentos corporais, mas fortemente é feita essa relação com a homossexualidade.

\section{Caminhos metodológicos}

\footnotetext{
${ }^{3}$ O romantismo na dança promove uma valorização da mulher em cena como uma representação de um ideal-mulher inacessivel: uma imagem do ideal sonhado pelos homens. Seu marco principal foi com a obra 'La Sylphide', de Marie Taglioni, na década de 1830. Como afirma Judith Hanna (1999, p.188), Taglioni "sintetizou a fantasiosa e etérea peça central da era romântica, em La Sylphide".
}

Movimento, Porto Alegre, v. 17, n. 01, p. 159-175, janeiro/março de 2011. 
Essa investigação situou-se no campo dos estudos pós-estruturalistas de gênero. Como observa Harding (2003), tal perspectiva exige que o pesquisador esteja implicado com o universo de pesquisa, ao invés de procurar buscar uma neutralidade. Dessa maneira, eu, um homem heterossexual, que já teve certa experiência com dança ${ }^{4}$, decidi problematizar a construção das masculinidades na dança.

Esse tipo de investigação, como observa Bandeira (2009), apresenta o risco de tomar algumas práticas como óbvias ou dadas. Velho (2003, p. 15) chama esse obstáculo de "o desafio da proximidade", afirmando que o pesquisador deve ser capaz de conseguir estranhar o que lhe é familiar. Assim, tendo eu já um envolvimento com a dança, procurei aqui abrir possibilidades para as vozes de outros bailarinos. Nesse percurso, me esforcei por tentar desnaturalizar e desfamiliarizar em mim aquilo que já estava naturalizado e familiarizado.

A aproximação com o campo de pesquisa se deu, inicialmente, a partir da adoção de uma abordagem de inspiração etnográfica, através da qual mapeei diferentes grupos de dança contemporânea de Porto Alegre. Essa aproximação contou com a minha presença em aulas, ensaios e atividades de criação coreográfica. Busquei investigar três grupos diferentes, visando dar conta minimamente da diversidade de masculinidades possíveis nesse universo. A partir desse mapeamento inicial do campo, foram elaboradas questões para um questionário de entrevistas, e elegi alguns bailarinos onde esse questionário seria aplicado. A produção dos materiais de análise para essa pesquisa se deu a partir das narrativas advindas dessas entrevistas.

Utilizei como critério de seleção dos participantes: a) ser homem, (independente da orientação sexual, idade, etnia, classe social, etc); b) ser bailarino de dança contemporânea, independente de também praticar ou não alguma outra dança (quase todos praticavam balé, por exemplo); c) ter um envolvimento significativo com a dança (estar envolvido em algum tipo de produção artística, além

${ }^{4}$ Essa experiência inicia-se com diversas aulas esporádicas de dança que fiz ao longo dos anos de 2004 e 2005. Em 2006, trabalhei em um espetáculo na Companhia Joca Vergo de Dança Contemporânea, em Porto Alegre. Em 2007, trabalhei no Circo Internacional Espanhol, com um número de dança aérea.

Wovimento, Porto Alegre, v. 17, n. 01, p. 159-175, janeiro/março de 2011. 
do mero treinamento cotidiano em aulas); d) dar prioridade para bailarinos, e não para coreógrafos, buscando com isso evidenciar posições sociais de menor poder.

Participaram deste estudo 8 homens, sendo que 6 eram apenas bailarinos, e dois eram bailarinos mas também coreógrafos, devido à dificuldade de isolar, no campo empírico, o critério "d". Todos os entrevistados eram residentes de áreas urbanas e de classe média do Estado do Rio Grande do Sul, com idades entre 19 e 30 anos. Foi utilizada a metodologia de amostragem do tipo bola de neve ${ }^{5}$, isso é, a partir de dois sujeitos iniciais, conhecidos pelo pesquisador, foram selecionados outros sujeitos que eles conheciam, repetindo-se o processo sucessivamente até não haverem novas indicações. Foram realizadas entrevistas individuais conforme a disponibilidade dos sujeitos, sendo gravadas e transcritas na íntegra para análise posterior.

As entrevistas foram orientadas por um roteiro semi-estruturado. As questões centraram-se em: como esses homens chegam a dançar em uma cultura onde a dança é hegemonicamente significada como prática não-masculina? E como estruturam estratégias e negociações para a produção e manutenção da identidade masculina?

A partir dessas falas, procurei não interpretar ou decifrar aquilo que os bailarinos pensam de si mesmos e da dança, ou o que querem dizer, mas sim mapear os modos como eles narram a si mesmos enquanto sujeitos de gênero. Procurei encontrar aí recorrências que me permitiram pensar as representações culturais de masculinidades que mais circulam hoje em dia no contexto da dança contemporânea. Assim, ao utilizar fragmentos de falas e depoimentos, optei por um trabalho de confrontação entre diferentes narrativas, aproximado os relatos de diferentes bailarinos, de forma a estabelecer relações e articulações entre as diferentes significações que aparecem neles.

\footnotetext{
${ }^{5}$ A amostragem via bola de neve (do inglês snowball sampling) é uma técnica na qual os sujeitos que irão fazer parte da pesquisa são indicados diretamente pelos próprios pesquisados. De acordo com tal técnica, pergunta-se a um predeterminado grupo de atores sociais ('zona de primeira ordem' (GOODMAN, 1961, apud WASSERMAN; FAUST, 1999, p. 34) ou 'primeiro estágio' (ROTHENBERG, 1995, p.105)) com quem ele tem laços, resposta que serve como indicação do próximo grupo de atores na rede a ser pesquisado. A pesquisa prossegue até que não sejam indicados novos sujeitos.
}

Movimento, Porto Alegre, v. 17, n. 01, p. 159-175, janeiro/março de 2011. 


\section{Resultados E dISCUSSÃO}

De acordo com as questões de pesquisa dispus a análise do corpus das entrevistas em cinco eixos. $\mathrm{O}$ primeiro eixo, intitulado "narrativas do masculino na dança", analisa as características das trajetórias de vida para homens no universo da dança, problematizando as formas como esses homens chegam a dançar. Ele evidencia que, num sentido geral, as trajetórias de vida são diferentes para homens e para mulheres, em virtude dos diferentes investimentos que a cultura faz sobre os gêneros.

Ao narrarem suas experiências de vida na dança, os sujeitos entrevistados reforçaram as constatações de Andréa Bitencourt Souza (2007) sobre o universo da dança porto-alegrense, onde os homens são minoria e parecem precisar primeiro driblar um conjunto de representações culturais que funcionam simbolicamente como "barreiras" de gênero para que enfim a prática da dança possa ser vivenciada por eles. Quase todos os bailarinos entrevistados narraram ter tido um começo tardio na dança, com mais de vinte anos, por não terem se identificado com essa prática corporal desde a infância. Diferentemente das mulheres ${ }^{6}$, o contexto e o meio social não estimula a prática da dança para os homens mais cedo. Pelo contrário, a inibe.

Tais "barreiras" para a inserção dos homens na dança foram referenciadas geralmente ao meio social, como a família, os amigos ou cônjuges. Através de uma forte regulação da vida desses sujeitos, a partir de normas de gênero, esse entorno social atuou, ao longo de suas vidas, como elemento marcante. Foi também recorrente a preocupação em regular a sexualidade dos sujeitos, em corrigir o possível "desvio" da homossexualidade, dentro de uma lógica cultural homofóbica. Nesse sentido, o pai, por ser uma figura representativa da masculinidade hegemônica, dentro de um modelo de família heterossexual, foi apontado como muito significativo.

\footnotetext{
${ }^{6}$ No caso das mulheres, por outro lado, como observa Tatiana Mielczarski. Santos (2009), o gênero parece atuar num sentido favorável para que a prática da dança seja vivenciada desde a infância, sendo o aprendizado dos seus gestos corporais simbolicamente associado com o aprendizado de modos de ser "feminino".
}

Movimento, Porto Alegre, v. 17, n. 01, p. 159-175, janeiro/março de 2011. 
Além da representação cultural da dança no sentido geral como associada à homossexualidade, os obstáculos sociais apontados referiram-se também a uma condição de "artista". Para os sujeitos da pesquisa, o campo artístico em geral, e não somente a dança, parece ser representado como algo que geralmente não é bem visto para um projeto de vida bem sucedido de aquisição da masculinidade. Isso apareceu nas entrevistas realizadas como muito ligado ao fato de a profissão de artista não ser bem remunerada, e não garantir a certeza de um sucesso econômico.

No segundo eixo, intitulado "o bailarino self made" analiso as decorrências dessa conjuntura nas atitudes e opções de vida desses sujeitos, ou seja, como esses homens que chegaram a dançar procuraram lidar com tudo isso. A pesquisa evidencia que eles geralmente precisam "provar" a sua virilidade perante a sociedade ao se envolverem com a dança, uma vez que "ser aceito socialmente é uma condição para o masculino vir a dançar." (SOUZA, A. B., 2007, p.74). Assim, "ser muito bom" em dança aparece como uma das estratégias utilizadas por esses sujeitos para serem aceitos socialmente. Assim, eles procuram superar as deficiências no domínio das técnicas, pelo fato de terem começado muito tarde, dedicando-se à dança muito intensamente, pois o talento técnico legitima e valida uma "verdadeira" identidade masculina.

Além disso, a pesquisa evidencia que a preocupação que permeia o universo masculino em torno da questão do "ser bem sucedido na vida" também é marcante no que diz respeito a suas escolhas. Por exemplo, muitos sujeitos entrevistados narraram que só começaram a fazer aulas de dança depois dos vinte anos porque só então tinham condições de pagar suas próprias aulas, sem terem que prestar contas economicamente à família pelo fato de estarem dançando. Assim é importante ressaltar que, para esses sujeitos, exibir uma certa capacidade para auto-gerir-se, exibindo certa autonomia fincanceira, uma das marcas da masculinidade hegemônica, também revelou-se como uma eficiente estratégia para obter uma melhor aceitação social.

Nessa direção, é observável que a intensa dedicação corporal com vistas a obter uma absoluta perfeição técnica faz com que a

Movimento, Porto Alegre, v. 17, n. 01, p. 159-175, janeiro/março de 2011. 
dança acabe ocupando uma certa centralidade na vida desses homens, como já observara Souza (2007) mas acabe articulando-se a um desejo de obter ganhos financeiros através da dança. Pelo fato da dança não representar uma área de investimento com garantias de se tornar rentável no caminho de vida desses homens, é muito comum então que eles sejam gradualmente impelidos a galgar posições de maior poder dentro desse universo: primeiro bailarinos, depois professores, produtores culturais e por fim coreógrafos.

Assim, a pesquisa indica elementos significativos para pensar a conjuntura que autores da literatura internacional como Van Dyke (1992) ou Stinson (1995) tem problematizado, quando observam que há em geral poucos bailarinos homens em companhias de dança em todo mundo, mas há sempre um número muito grande deles ocupando posições de poder, como coreógrafos e dirigentes. $\mathrm{Na}$ perspectiva de análise aqui apontada, é a existência de um modelo cultural de valorização do masculino, calcado em um certo "espírito empresarial" que deve ser levado em conta.

Como observa Lipovetsky (2000, p. 291), na sociedade contemporânea, os homens e mulheres "não são igualmente encorajados a lançar-se na corrida aos títulos e às posições sociais", e "as competições pelo prestígio não se beneficiam de uma mesma imagem no masculino e no feminino". Isso se dá pela existência de normas e as sociais e identitárias diferenciais para o masculino e o feminino. Essas normas orientam preferencialmente o feminino para o relacional e o íntimo, e o masculino para a independência, a "instrumentalidade" e a eficácia social (LIPOVETSKY, 20001 p. 303). Sendo assim, o espírito de autonomia e de sucesso são mais estimulados pela educação dos homens do que pela das mulheres.

Isso possui uma estreita ligação com o que Kimmel (1998) nomeia como um dos principais modelos hegemônicos de masculinidades na nossa época: o self made man. Neste contexto, essa representação cultural hegemônica, orientada em torno do desejo por sucesso, glória, renome e eficiência econômica, leva os homens a terem uma experiência diferente daquela que as mulheres têm com a dança. Ao contrário do que acontece com as mulheres, onde

Movimento, Porto Alegre, v. 17, n. 01, p. 159-175, janeiro/março de 2011. 
dançar não é diretamente associado com ganhos econômicos, pois a dança é tida como uma prática própria da "natureza" feminina, essa lógica cultural os leva a encararem a dança muito mais como um investimento profissional do que como algo estéticoOutras estratégias apontadas pelos entrevistados como caminhos para a validação da masculinidade em suas trajetórias de vida foram a vinculação a outras práticas. Essa questão é analisada no terceiro eixo, intitulado “o início prévio em outras praticas corporais". Nesse eixo, analiso como a trajetória de vida dos entrevistados aparece sempre atravessada com a prática de esportes e outras atividades físicas, culturalmente consideradas como mais próprias para o masculino. De acordo com a pesquisa, é possível considerar que outras práticas corporais, muitas vezes consideradas mais "viris" servem para ir legitimado, para os outros mas também para eles mesmos, sua aproximação gradual à dança. Em especial a articulação entre dança e esporte, ou, muitas vezes, a significação da dança "como se fosse" um esporte.

Essa associação entre dança e esporte é recorrente ao longo da história. Como observa Hanna (1999), na segunda metade do século $\mathrm{XX}$, durante a década de 80 , ocorreu um movimento significativo na dança ocidental em reação à atitude negativa da sociedade para com homens que dançavam. Essa tentativa de um ressurgimento dos homens na dança foi acompanhada por uma vontade de promover a dança como uma prática atlética. Em paralelo a essa tentativa de valorizar os bailarinos considerando-os como "atletas", se invocava com frequência também o seu sucesso econômico.

No quarto eixo, "dança e homossexualidade", analiso o impacto da forte representação cultural que associa a prática da dança por homens à homossexualidade, num sentido negativo (homofóbico): como se a homossexualidade fosse uma espécie de degradação da "verdadeira" masculinidade. A pesquisa evidencia que essa associação diz respeito, predominantemente, ao balé clássico. Entretanto, reforça a constatação de Andréa Bittencourt de Souza (2007) de que o balé clássico configura-se como um cânone estético para todo o universo da dança. Isso faz com que essa associação permeie todas as danças em geral, inclusive a dança contemporânea. A pesquisa indica que essa associação apresentou-se como um obstáculo muito

Movimento, Porto Alegre, v. 17, n. 01, p. 159-175, janeiro/março de 2011. 
mais problemático, na vida desses sujeitos, do que a associação da dança com a feminilidade.

Os entrevistados encontraram formas diferentes de lidar com essa questão. No caso dos homens que se auto-identificaram como heterossexuais, a validade da sua masculinidade parece ser chancelada e aprovada pelo ato da conquista amorosa. Nesse caso, a atividade sexual aparece como uma prova através da qual os valores da masculinidade hegemônica são alcançados. Também foi observada a afirmação de um estilo de vida moralmente correto, não associado à excessiva libertinagem sexual, ou ao uso de drogas, toda marcas negativas do meio artístico perante o imaginário social. Um homem capaz de manter um comportamento moralmente correto estaria, assim, apesar de estar envolvido com dança, tendo sua masculinidade assegurada.

No caso de homens auto-identificados como não-heterossexuais, a associação da dança com a homossexualidade foi apontada como um obstáculo apenas no sentido de reforçar a dificuldade de aceitação, da parte deles mesmos, de uma orientação de vida não-heterossexual, em sua associação com certas práticas sociais. No entanto, quando a situação é oposta, e o caso é de uma busca por uma orientação não-heterossexual, a associação da dança com homossexualidade parece facilitar a busca por essa identidade. A dança, assim, parece ser um meio social onde as demais formas de sexualidade são melhor aceitas. Mais do que isso, a opção por dançar, entendida como uma ruptura com as normas que dizem que um homem não deve dançar, é uma transgressão similar e equivalente à opção por se assumir como não-heterossexual, em uma cultura que diz que todos os seres humanos devem ser heterossexuais.

No quinto eixo, "a polaridade masculino e feminino e a dança contemporânea" analiso as representações específicas dentro do universo da dança contemporânea, no que diz respeito ao gênero. A pesquisa evidencia uma contradição no que se refere à forma como a dança contemporânea anuncia-se como mais "livre" do que as outras danças, como capaz de transgredir, em cena, quaisquer normas referente ao uso dos corpos dos artistas, e no entanto, parece manter

Movimento, Porto Alegre, v. 17, n. 01, p. 159-175, janeiro/março de 2011. 
as mesmas normatizações estéticas de gênero do balé clássico, no que diz respeito a elementos como a presença cênica de homens e de mulheres. Assim, por exemplo, o masculino é relacionado ao "forte", ao "bruto" e o feminino ao "suave", "delicado", não devendo inverter-se esses papéis: ou seja, não devendo os homens atuarem cenicamente com movimentos suaves e leves, e nem as mulheres com movimentos mais fortes ou explosivos.

\section{ConCLUSÃo}

O universo empírico investigado permitiu discutir a produção da representação cultural hegemônica de masculinidade, independente da orientação sexual dos sujeitos entrevistados e considerando as variações observadas na vivência de cada um. Os resultados em comum trazem importantes reflexões para uma melhor compreensão sobre o processo de formação dessas representações e práticas, fortemente entrelaçados com a história e o contexto sócio-cultural da moderna sociedade capitalista, onde as características exigidas para o verdadeiro comportamento dos homens são: objetividade, eficiência, racionalidade, autonomia, espírito de independência e sucesso econômico. Dessa forma, foi possível observar como mesmo os indivíduos que assumem vivências distintas desse padrão hegemônico - homem que "ousam" dançar - ainda se pautam, em certo sentido, nesse modelo de masculinidade.

Com relação à primeira questão de pesquisa, acerca de como os homens em nossa cultura chegam a dançar, é possível perceber que seus caminhos de vida são muitas vezes similares e que eles enfrentam obstáculos parecidos. Tais obstáculos são referentes principalmente à condição de artista como profissão de baixa renda e à associação da dança com a homossexualidade. Trajetórias similares também revelam-se quando quase todos eles começam a dançar depois da maior idade, preocupam-se com a autonomia financeira e passam antes por esportes e outras práticas corporais.

Com relação à segunda pergunta, referente a que estratégias eles utilizam para legitimarem suas masculinidades, a pesquisa evi-

Movimento, Porto Alegre, v. 17, n. 01, p. 159-175, janeiro/março de 2011. 
dencia que parece só ser socialmente aceitável um homem dançar em nossa cultura quando ele exibe alguns dos traços característicos das representações hegemônicas de masculinidade. É como se a cultura nos interpelasse no sentido de nos dizer: "homens, a princípio, não dançam, mas se algum homem, mesmo assim, dançar, que pelo menos comprove que, apesar de dançar, ainda é um homem, dançando excepcionalmente bem, encarando a dança como uma carreira, ocupando posições de destaque e sendo economicamente bem sucedido."

Com relação às características específicas do universo da dança contemporânea, a pesquisa constatou que existiu pouca apropriação por parte dos bailarinos de um discurso consistente sobre suas práticas. Mesmo falando de dança contemporânea eles falaram com referenciais de gênero oriundas do balé. Embora a dança contemporânea anuncie uma retórica de transgressão e ruptura, isso não pareceu migrar para as concepções e posições de gênero que eles enunciaram, e que procuram adotar em suas vidas. Deve-se levar e conta que a pesquisa é situada em um contexto regional, e que fez um recorte de apenas oito bailarinos. No entanto, ela evidencia o quanto o balé ainda hoje dita normas tanto para a dança quanto para o gênero e a sexualidade.

Movimento, Porto Alegre, v. 17, n. 01, p. 159-175, janeiro/março de 2011. 
Cultural representations of contemporary dance

Abstract: This practical article approaches the cultural representations of male gender in the field of contemporary dance. For sustentation of the problematic one of the research, it launches hand of the theoretical referencial of the Cultural Studies and the post-structuralists studies of gender. It is used of the methodology of qualitative research, collecting information through interviews, to analyze narratives of dancers. The spread out idea of the dance argues sufficiently as something more associated the women or men homosexuals, perception that acts as a barrier to the ingression of the men in any rhythmic or expressive activities

Keywords: Dancing. Gender identity. Human body. Masculinity.

\begin{tabular}{|l|}
\hline Representaciones culturales de la danza contem- \\
poránea \\
Resumen: En este artículo se analizan los vínculos \\
entre las representaciones culturales del genero \\
masculino y la danza contemporánea. Para apoyar \\
el problema de investigación, utiliza el marco teórico \\
de los estudios culturales y estudios de género post- \\
estructuralistas. Utiliza la metodología de investigación \\
cualitativa, la recopilación de información através de \\
entrevistas, para analizar las narrativas de los bailar- \\
ines. Explica la idea generalizada de que la danza es \\
algo más asociado con las mujeres o los hombres \\
homosexuales, la percepción de que actúa como una \\
barrera de entrada para los hombres en cualquier \\
actividad rítmica o expresiva. \\
Palabras clave: Baile. Identidad de género. Cuerpo \\
humano. Masculinidad.
\end{tabular}

\section{REFERÊNCIAS}

ANDREOLI, Giuliano Souza. Dança, gênero e sexualidade: um olhar cultural. Conjectura, Caxias do Sul, v. 15, n. 1, p. 107-118, jan./abr. 2010b.

ANDREOLI, Giuliano Souza. Representações de masculinidade na dança contemporânea. 2010. 137 f + anexos. Dissertação (Mestrado) - Faculdade de Educação, Universidade Federal do Rio Grande do Sul, Porto Alegre, 2010a.

BADINTER, Elisabeth. XY: sobre a identidade masculina. Rio de Janeiro: Nova Fronteira, 1993.

Movimento, Porto Alegre, v. 17, n. 01, p. 159-175, janeiro/março de 2011. 
BANDEIRA, Gustavo Andrada. Eu canto, bebo e brigo... alegria do meu coração: currículo de masculinidades nos estágios de futebol. 2009. 128f. Dissertação (Mestrado). - Faculdade de Educação, Programa de Pós-Graduação em Educação, UFRGS, Porto Alegre, 2009.

BEAUVOIR, Simone de. O segundo sexo. 10. ed. Rio de Janeiro: Nova Fronteira, 2000.

BONOMO, Mariana; BARBOSA, Paola Vargas; TRINDADE, Zeidi Araujo. Homens: gênero e identidade em grupos tradicionais, metrossexuais e homossexuais no Brasil. Revista eletrônica de Psicologia Política, San Luis, v. 9, n. 17, p. 1-22, ago. 2008.

BRITZMAN, Deborah. O que é esta coisa chamada amor? identidade homossexual, educação e currículo. Educação e Realidade, Porto Alegre, v. 21, n. 1, p. 71-76, jan./jun. 1996.

BUTLER, Judith. Problemas de gênero: feminismo e subversão da identidade. Rio de Janeiro: Civilização Brasileira, 2003.

CUNHA JUNIOR, Carlos Fernando F. Gênero e História: Apontamentos de uma pesquisa sobre masculinidade e Educação Física. In: CONGRESSO BRASILEIRO DE HISTÓRIA DA EDUCAÇÃO FÍSICA, ESPORTE, LAZER E DANÇA, 7., 2000, Gramado. Anais..., Gramado: ESEF/UFRGS, 2000. v 2, p. 396-400.

GOELLNER, Silvana Villodre. Gênero, Educação Física e Esportes. In: VOTRE, S. B. (Org.). Imaginário e representações sociais em Educação Física, Esporte e Lazer. Rio de Janeiro: UGF, 2001. p. 215-227.

HANNA, Judith Lynne. Dança, sexo e gênero: signos de identidade, dominação e desejo. Rio de Janeiro: Rocco, 1999.

HARDING, Sandra. Ciência e tecnologia no mundo pós-colonial e multi-cultural: questões de gênero. Labrys: estudos feministas, Brasília, n. 3, jan./jul. 2003. Disponível em: http://vsites.unb.br/ih/his/gefem/labrys3/web/bras/sandra1.htm. Acesso em: 13 ago. 2010.

KIMMEL, Michael. A produção simultânea de masculinidades hegemônicas e subalternas. Horizontes Antropológicos, Porto Alegre, v. 4, n. 9, p.103-17, out. 1998.

LIPOVETSTY, Gilles. A terceira mulher: permanência e revolução do feminino. São Paulo: Companhia das letras, 2000.

LOURO, Guacira Lopes. Um corpo estranho: ensaios sobre sexualidade e teoria queer. Belo Horizonte: Autêntica, 2004.

MEYER, Dagmar; E. Estermann. Teorias e políticas de gênero: fragmentos de história e desafios atuais. Revista Brasileira de Enfermagem, Rio de Janeiro, v. 57, n. 1, p. 13-18, jan./fev. 2004.

ROTHENBERG, Richard B. Commentary: sampling in social networks. Connections, South Florida, v. 18, n. 1, p. 104-110, 1995.

Wovimento, Porto Alegre, v. 17, n. 01, p. 159-175, janeiro/março de 2011. 
SANTOS, Éderson Costa. Um jeito masculino de dançar: pensando a produção das masculinidades de dançarinos de hip-hop. Dissertação (Mestrado) - Faculdade de Educação, Universidade Federal do Rio Grande do Sul, Porto Alegre, 2009.

SANTOS, Tatiana Mielczarski. Entre pedaços de algodão e bailarinas de porcelana: a performance artística do balé clássico como performance de gênero. Dissertação (Mestrado). - Faculdade de Educação, Universidade Federal do Rio Grande do Sul, Porto Alegre, 2009.

SARAIVA, Maria do Carmo. Dança e Gênero na Escola: formas de ser e viver mediadas pela Educação Estética. 2003. 451f. Tese (Doutorado) - Faculdade de Motricidade Humana/UTL, Lisboa, 2003.

SCOTT, Joan. Gênero: uma categoria útil de análise histórica. Educação e Realidade, Porto Alegre, v.20, n. 2, p. 71-99, 1995.

SOUZA, Andréa Bittencourt de. Cenas do masculino na dança: representações de gênero e sexualidade. Ensinando modos de ser bailarino. Dissertação (Mestrado) - Faculdade de Educação, ULBRA, Canoas, 2007.

SOUZA, Eustáquia Salvadora. Meninos, à Marcha! Meninas, à Sombra: a história do ensino da educação física em Belo Horizonte. Tese (Doutorado) - Faculdade de Educação, UNICAMP, Campinas, 1994.

STINSON, Susan. Uma pedagogia feminista para a dança da criança. Proposições, UNICAMP,v. 6 .n. 3, p. 77-89, nov. 1995.

VAN DYKE, Jan Ellen. Modern dance in a post-modern world. Reston: American Alliance for Health, Physical Education, Recreation and Dance. 1992.

VELHO, Gilberto. O Desafio da Proximidade. In: VELHO, Gilberto; KUSCHNIR, Karina (Orgs.). Pesquisas Urbanas: desafios do trabalho antropológico. Rio de janeiro: Jorge Zahar, 2003.

WASSERMAN, Stanley; FAUST, Katherine. Social network analysis: methods and applications. In: Structural analysis in social the social sciences series. Cambridge: Cambridge University, 1994. v. 8.

Movimento, Porto Alegre, v. 17, n. 01, p. 159-175, janeiro/março de 2011. 